\title{
Dysaesthesiae induced by physiological and electrical activation of posterior column afferents after stroke
}

\author{
William J Triggs, Aleksandar Berić
}

\begin{abstract}
Six of 48 stroke patients had functionally limiting dysaesthesiae induced by repetitive light touch, joint movement, or neuromuscular electrical stimulation (NMS). Only one of these six patients had a thalamic lesion. Quantitative sensory testing showed substantial impairment of pain and temperature sensation in all six patients, whereas light touch, vibration and position sense, and graphaesthesia were normal (three patients) or relatively spared (three patients). By contrast, none of 15 stroke patients in whom NMS did not evoke dysaesthesiae had clinical evidence of dissociated sensory loss. Conscious perception of joint movement and light touch is mediated mainly by the same population of large myelinated fibres activated preferentially by low intensity electrical stimulation. It is suggested that activation of these nonnociceptive, presumably dorsal column, afferents may contribute to dysaesthesiae in some patients with sensory loss after stroke.
\end{abstract}

$(\mathcal{F}$ Neurol Neurosurg Psychiatry 1994;57:1077-1081)

Pain and dysaesthesiae have been associated with sensory loss since the description of the thalamic syndrome by Dejerine and Roussy. ${ }^{1}$ Dysaesthesiae indistinguishable from those occurring in thalamic syndrome or thalamic pain also complicate extrathalamic stroke. ${ }^{2-8}$ Whereas these sensory phenomena may seem to be spontaneous, they are more commonly evoked with innocuous somatic sensory stimulation, ${ }^{2-4}$ and such "painful over-reaction to objective stimulation" is a hallmark of central pain syndromes. ${ }^{2}$ Indeed, Kendall suggested that all central pain arises from external stimulation, and preferred to describe such phenomena as dysaesthesiae. ${ }^{9}$

At the level of the spinal cord, dysaesthesiae are associated with physiological ${ }^{10-12}$ and anatomical ${ }^{13-15}$ evidence of neospinothalamic deafferentation, with relative sparing of dorsal columns. We have suggested previously that dorsal column sparing in such patients is more than coincidental, and that dorsal column activation may contribute to the development of dysaesthesiae in patients with neospinothalamic lesions. ${ }^{10-12}$ We have even found disinhibition of somatosensory evoked potentials in a patient with the anterior spinal artery syndrome, consistent with this hypothesis. ${ }^{16}$ In stroke, many patients with dysaesthe- siae have lesions that affect the function of the neospinothalamic tract-that is, appreciation of pin prick and temperature. ${ }^{45817}$ Because many of these patients also show preservation of sensory modalities attributable to the dorsal columns, ${ }^{18-20}$ we decided to look for evidence that activation of dorsal column afferents contributes to dysaesthesiae after stroke.

\section{Methods}

We reviewed the records of 48 stroke patients referred to the Division of Restorative Neurology, Baylor College of Medicine, Houston, Texas, for neurological rehabilitation, to identify patients with dysaesthesiae related to light touch or joint movement. The extent of each patient's stroke was determined with CT or MRI.

Eighteen of these 48 patients were treated with neuromuscular electrical stimulation (NMS) in an effort to improve the fatigue resistance of paretic muscles, or to possibly modulate spasticity. ${ }^{21}{ }^{22}$ Briefly, this technique consists of electrical stimulation of weak or hypertonic muscles with trains of transcutaneous stimuli $(20-50 \mathrm{~Hz})$ delivered through surface electrodes overlying the muscle belly. Stimulus intensity is adjusted to produce repetitive contraction of the affected muscle without producing pain or muscle spasm. Stimulus variables are otherwise similar to those employed for transcutaneous electrical nerve stimulation (TENS). ${ }^{23}$

In patients identified as having dysaesthesiae, we tested sensory function with clinical and quantitative sensory testing. We tested light touch perception with Von Frey hairs, recording threshold as the lowest stimulus intensity detected in $>50 \%$ of trials. We determined vibration thresholds over the clavicle, second metacarpal, first metatarsal, and anterior tibia with a vibrameter (Somedic $A B$ ) by the method of Goldberg and Lindblom. ${ }^{24} \mathrm{We}$ assessed thermal sensibility over cervical, thoracic, lumbar, and sacral dermatomes with a thermotest thermal stimulator (Somedic AB) according to the method of Fruhstorfer et al..$^{25}$

\section{Results}

Six of 48 patients had functionally limiting dysaesthesiae induced or exacerbated by light touching or movement. None of the remaining 42 patients were affected with central pain. In three of the six patients with dysaesthesiae, these sensations were induced primarily by NMS. Table 1 summarises the clinical features of these six patients. Lesion 
Table 1 Clinical features of stroke patients with functionally limiting dysaesthesiae

\begin{tabular}{|c|c|c|c|c|c|}
\hline Patient & Age (y) & Sex & Neurological lesion & Neurological deficit & $\begin{array}{l}\text { Dysaesthesias } \\
\text { induced by }\end{array}$ \\
\hline 1 & 54 & $\mathbf{M}$ & $\begin{array}{l}\text { Right thalamic } \\
\text { haemorrhage }\end{array}$ & Left hemiparesis and sensory loss & $\begin{array}{l}\text { Repetitive light touch } \\
\text { Vibration }\end{array}$ \\
\hline 2 & 70 & $\mathbf{M}$ & Left parietal infarction & Right hemiparesis and sensory loss & $\begin{array}{l}\text { Electrical stimulation } \\
\text { Repetitive light touch }\end{array}$ \\
\hline 3 & 73 & $\mathbf{M}$ & $\begin{array}{l}\text { Left brainstem } \\
\text { infarction }\end{array}$ & Right hemiparesis and sensory loss & $\begin{array}{l}\text { Electrical stimulation } \\
\text { Joint movement }\end{array}$ \\
\hline 4 & 61 & $\mathbf{M}$ & $\begin{array}{l}\text { Left parietal } \\
\text { haemorrhage }\end{array}$ & Right hemiparesis and sensory loss & $\begin{array}{l}\text { Electrical stimulation } \\
\text { Repetitive light touch }\end{array}$ \\
\hline 5 & 68 & $\mathbf{F}$ & $\begin{array}{l}\text { Left middle cerebral } \\
\text { artery infarction }\end{array}$ & $\begin{array}{l}\text { Right hemiparesis and sensory loss } \\
\text { Broca's aphasia }\end{array}$ & $\begin{array}{l}\text { Repetitive light touch } \\
\text { Joint movement }\end{array}$ \\
\hline 6 & 42 & $\mathbf{F}$ & Brainstem infarction & $\begin{array}{l}\text { Left sided sensory loss } \\
\text { Quadriparesis }\end{array}$ & $\begin{array}{l}\text { Repetitive light touch } \\
\text { Joint movement }\end{array}$ \\
\hline
\end{tabular}

location was variable, including brainstem and cortical regions; only one patient had a thalamic lesion. Each of these six patients had impaired thermal discrimination and pin prick sensibility (table 2). Light touch, position sense, graphaesthesia, and vibratory sensibility were normal (patients 1-3) or only variably affected (patients 4-6). By contrast, none of 15 patients in whom NMS did not induce dysaesthesiae showed clinical evidence of dissociated loss.

\section{PATIENT 1}

This 54 year old man developed left sided sensory loss and hemiparesis after a right thalamic haemorrhage. At the onset of his neurological deficit, he noted dysaesthesiae described as "intensely uncomfortable sensations, not pain." These sensory abnormalities affected the left side of his face, neck, and trunk, to the level of his waist. The sensations were also experienced throughout his left leg, but were less intense. Thermal discrimination and pin prick sensibilities were impaired throughout his left side. By contrast, the thresholds for detection of vibratory and tactile stimulation of deafferented regions were normal, but caused allodynia, interpreted as a distressing "burning-tingling sensation" spreading from the site of stimulation. Position sense and graphaesthesia were normal. Phenytoin, carbamazepine, and amitriptyline had no effect on dysaesthesiae. Electrical stimulation through electrodes implanted in the thalamus ${ }^{26} 272.5$ years after the onset of symptoms caused some improvement.

\section{PATIENT 2}

This 70 year old physician developed right hemiparesis and sensory loss after a left parietal infarction. Six months later, he noted "burning" dysaesthesiae during movement of his paretic right arm. These improved with amitriptyline and gradually subsided; amitriptyline was discontinued. Eight years later, we evaluated him for rehabilitation. He had hemiparesis and decreased pin prick and temperature perception over his entire right side. Vibratory and position sense, light touch perception, and graphaesthesia were normal. Treatment of his spastic right arm with NMS was initially tolerated, but was stopped after several sessions due to recrudescence of his original "burning" dysaesthesiae, extending up the arm and over the anterior thoracic region. These dysaesthesiae were directly related to repetitive light touching of the arm, which now elicited reflex withdrawal. These sensations did not persist beyond the duration of light mechanical stimulation.

\section{PATIENT 3}

This 73 year old man developed a right hemiparesis and sensory disturbance after a left brainstem infarction. He noted mild right sided dysaesthesiae during the next two years, described as an unpleasant "heavy sensation" of "muscles pulling" during movement of his arm and leg. These sensory abnormalities affected his entire right arm, the lateral aspect of his right chest, and the anterior aspect of his right leg. A right foot drop persisted as his most significant problem. Thus four years after his stroke he was referred for NMS. He had impairment of pin prick and thermal sensibilities, and mild impairment of vibration. Light touch, position sense, and graphaesthesia were normal. Dorsiflexion strength seemed to be improved by NMS, but after several weeks it caused increasingly intolerable exacerbation of the patient's sensation of "heaviness" in his arm and leg. Although the patient noted that NMS helped him to walk, he could no longer tolerate the stimulation. Interestingly, movement of his right arm now worsened dysaesthesiae in his right leg, and vice versa.

\section{PATIENT 4}

This 61 year old man developed right hemiparesis and "burning" dysaesthesiae after a

Table 2 Quantitative sensory testing in stroke patients with dysaesthesias

\begin{tabular}{llllllll}
\hline & $\begin{array}{l}\text { Temperature } \\
\text { Patient }\end{array}$ & $\begin{array}{l}\text { Thermal } \\
\text { pain } \\
\text { discrimination }\end{array}$ & $\begin{array}{l}\text { Pin prick } \\
\text { sensibility }\end{array}$ & $\begin{array}{l}\text { Light touch } \\
\text { Von Frey } \\
\text { hairs }\end{array}$ & $\begin{array}{l}\text { Vibratory } \\
\text { sensation }\end{array}$ & Graphaesthesia & $\begin{array}{l}\text { Position } \\
\text { sense }\end{array}$ \\
\hline 1 & 1 & 1 & 1 & 0 & 0 & 0 & 0 \\
2 & 1 & 2 & 1 & 0 & 0 & 0 & 0 \\
3 & 2 & 1 & 1 & 0 & 1 & 0 & 1 \\
4 & 2 & 1 & 1 & 1 & 1 & 1 & 1 \\
5 & 2 & 2 & 2 & 2 & 2 & 2 & 1 \\
6 & 2 & 1 & 2 & 0 & 0 & NT & 0 \\
\hline
\end{tabular}

$0=$ Normal; $1=$ threshold $2-5$ times higher on symptomatic side; $2=$ threshold $>5$ times higher or perception absent on symptomatic side (modified from Boivie et $\left.a l^{4}\right) ; \mathrm{NT}=$ not tested. 
left parietal haemorrhage. These sensory abnormalities affected the entire right hemibody. Three years later, he was referred for NMS to treat dorsiflexion weakness. He had a spastic right hemiparesis with right sided sensory loss; temperature discrimination was severely impaired and all other sensory modalities were moderately affected. Repetitive light touching and vibration aggravated the "burning" dysaesthesiae. When used as a functional prosthesis, NMS seemed to improve his gait, but increasingly worsened his dysaesthesiae, and was discontinued at his insistence.

\section{PATIENT 5}

This 68 year old woman developed a Broca's aphasia with right hemiparesis and sensory loss after a left middle cerebral artery stroke. When evaluated two months after the stroke, she had severe impairment of all sensory modalities, but with relative sparing of position sense. In physical therapy sessions, she developed gradual intolerance to passive manipulation of the fingers or wrist of her plegic right hand. Although non-fluent, she expressed her displeasure with striking facial grimacing during passive movement or repetitive light touching of her right arm.

\section{PATIENT 6}

After chiropractic cervical manipulation, this 42 year old woman developed a spastic tetraparesis, diplopia, sensory disturbance, and a brainstem infarction. Angiography showed occlusion of the right vertebral artery. Five months after the stroke, she had involvement of the right third and fourth cranial nerves, right sided dysmetria, and a spastic tetraparesis. She had impaired pin prick sensibility throughout her left arm and leg, but light touch, vibration, and position sense were normal. She complained bitterly about "deep aching" and "burning" sensations precipitated by repetitive light touching or movement of her left arm or leg. These sensory abnormalities predominantly affected her left hand and her entire left leg. She considered volitional leg movement impossible because of these dysaesthesiae.

\section{Discussion}

We noted that somatic stimulation induced dysaesthesiae in six of 48 patients after stroke. We analysed sensory function in these patients to clarify this phenomenon. With quantitative sensory testing, we found substantial impairment of pin prick and temperature sensibilities in all patients, virtually a consistent finding in patients with dysaesthesiae after stroke. ${ }^{4}$ Sensibilities attributable to dorsal column function ${ }^{18-20}$ were, however relatively preserved in our patients. This finding is similar to the experience of other investigators, ${ }^{48}$ including findings of "thalamic pain" in patients with normal somatosensory evoked potentials. ${ }^{17}$ Non-noxious, somatic stimulation may also produce or exacerbate dysaesthesiae in patients with traumatic spinal cord injury, ${ }^{10}$ anterior spinal artery syndrome, ${ }^{11}$ and anterolateral cordotomy. ${ }^{28}$ These patients all have impairment of neospinothalamic pathways, with relative preservation of the dorsal columns.

Our patients had dysaesthesiae induced by repetitive light touch, vibration, and joint movement. Under normal circumstances, such mechanoreceptive stimuli probably activate low threshold, myelinated, dorsal column afferents. ${ }^{18-20}$ Similarly, NMS, ${ }^{22}$ which caused dysaesthesiae in three of our patients, probably produces preferential activation of large diameter, non-nociceptive afferents, ${ }^{29}{ }^{30}$ innervating both skin and muscle. As our patients experienced dysaesthesiae with low intensity tactile and electrical stimulation, our findings suggest either an abnormal CNS response to physiological stimulation of large myelinated afferents, or sensitisation of primary nociceptors. $^{31}$ Clearly, nociceptive sensitisation ${ }^{32}$ seems an untenable explanation for our findings, in the absence of concomitant peripheral injury. Some findings, however, ${ }^{31}{ }^{33-36}$ indicate that physiological activation of low threshold, large myelinated fibres may induce dysaesthesiae associated with peripheral nerve injury.

In patients with injury to the CNS, dysaesthesiae induced by activation of large myelinated afferents may be related to dissociated sensory loss. Although our study was not prospective, we found that NMS was well tolerated by stroke patients without evidence of dissociated sensory loss on clinical examination. Transcutaneous electrical nerve stimulation (TENS) increased pain intensity in one third of patients with poststroke pain. ${ }^{37}$ Most of these patients had impaired temperature appreciation but relative sparing of epicritic sensibilities. ${ }^{45}$ Stimulus variables used for TENS are similar to those we used for NMS, and TENS activates large myelinated afferents. ${ }^{23}$ Treatment by TENS was also reported as being "intolerably painful" in a group of patients with "thalamic syndrome". ${ }^{38}$ Further, dysaesthesiae have been evoked or exacerbated by direct electrical stimulation of the dorsal columns in patients with dissociated sensory loss due to spinal cord lesions, ${ }^{101139}$ and during local anaesthesia. ${ }^{40}$ These findings are consistent with our hypothesis that activation of dorsal column afferents may cause dysaesthesiae in patients with lesions of neospinothalamic pathways.

Admittedly, our findings do not prove a causal role for the dorsal columns. Indeed, there is evidence of considerable redundancy in the transmission of sensory information associated with mechanoreceptive sensibilities, such as vibration and position sense..$^{41} 42$ (See Greenberg et $a l^{43}$ and Davidoff ${ }^{44}$ for reviews.) On the other hand, clinical studies have traditionally associated disorders of light touch, joint position, and vibration with abnormal somatosensory evoked potentials (SEPs). ${ }^{45}$ There is convincing experimental evidence that the dorsal columns are the primary neural substrate for SEPs in primates. ${ }^{46}$ In humans, Berić and colleagues found that preservation of thresholds for light touch and vibration correlated with preservation of SEPs in 110 patients with spinal cord injury studied 
with quantitative sensory testing. ${ }^{19}$ Even if the sensory information associated with discriminative sensibilities is not conveyed solely by the dorsal columns, the importance of our clinical findings is that pervasive, unpleasant sensations may accompany activation of nonnociceptive afferents in patients with central sensory abnormalities. The mechanisms for this misinterpretation of physiological sensory input are unknown. These phenomena, however, suggest the possibility ${ }^{1216}$ that neospinothalamic and associated pathways may normally have inhibitory influences on sensory input conveyed via non-nociceptive pathways.

In conclusion, we emphasise that our findings do not necessarily apply to all unpleasant sensations that may be experienced after stroke. To suggest otherwise would be implausible. For one thing, they seem to be directly opposite to those anticipated by the gate control theory of pain. ${ }^{47}$ Indeed, some patients with poststroke pain do obtain relief with non-noxious counterstimulation. ${ }^{37}$ Yet these apparent conflicts with our findings are only relevant if we suppose that all unpleasant sensations experienced after stroke reflect the same pathophysiological mechanism. Many of our patients observed that their dysaesthesiae were distinct from pains that they had experienced previously, and most of our patients did not experience any dysaesthesiae in the absence of somatic stimulation. Therefore, we suggest that our patients did not experience pain, but rather dysaesthesiae-abnormal physiological responses to non-noxious activation of somatic afferents. Thus our findings do not necessarily conflict with the gate control theory. Future prospective studies are required to further assess these issues, and to ascertain the incidence of dysaesthesiae after stroke.

We thank the Vivian L Smith Foundation for Restorative Neurology and the staff of the Division of Restorative Meurology and Human Nouston, Texas.

1 Dejerine J, Roussy G. Le syndrome thalamique. Rev Neurol 1906;14:521-32.

2 Riddoch G. The clinical features of central pain. Lancet 1938;i:1093-8.

3 Garcin R. Thalamic syndrome and pain of central origin. In: Soulairac A, Cahn J, Charpentier J, eds. Pain. London: Academic Press, 1968:521-41.

4 Boivie J, Leijon G, Johansson I. Central post-stroke paina study of the mechanisms through analyses of the sena study of the mechanisms through

5 Leijon G, Boivie J, Johansson I. Central post-stroke painneurological symptoms and pain characteristics. Pain 1989;36:13-25.

6 Pagni CA. Central pain due to spinal cord and brain stem damage. In: Wall PD, Melzack R, eds. Textbook of pain. London: Churchill Livingstone, 1989:634-55.

7 Tasker RR, Dostrovsky JO. Deafferentation and central pain. In: Wall PD, Melzack R, eds. Textbook of pain. London: Churchill Livingstone, 1989:154-80.

8 Schmahmann JD, Leifner D. Parietal pseudothalamic pain syndrome. Clinical features and anatomic correlates. Arch Neurol 1992;49:1032-7.

9 Kendall D. Some observations on central pain. Brain 1939;62:253-73.

10 Beric A, Dimitrijevic MR, Lindblom U. Central dysesthesia syndrome in spinal cord injury patients. Pain 1988;34: 109-16.

11 Triggs WJ, Beric A. Sensory abnormalities and dyesaesthesias in the anterior spinal artery syndrome. Brain 1992; 115:189-98.

12 Beric A. Central neurologic pains: "New" syndromes and their evaluations. Muscle Nerve 1993;16:1017-24.
13 Pagni CA. Central pain and painful anesthesia. Prog Neurol Surg 1976;8:132-257.

14 Nathan PW, Smith MC. Clinico-anatomical correlation in anterolateral cordotomy. In: Bonica JJ, Liebeskind JC, Albe-Fessard DG, Jones LE, eds. Advances in pain research and therapy. New York: Raven Press, 1979 921-6.

15 Nathan PW, Smith MC. Dysesthésie après cordotomie. Méd Hyg 1984;42:1788-90.

16 Triggs WJ, Beric A. Giant somatosensory evoked potentials in a patient with the anterior spinal artery syndrome. Muscle Nerve 1993;16:492-7.

17 Mauguière F, Desmedt JE. Thalamic pain syndrome of Dejérine-Roussy. Differentiation of four subtypes assisted by somatosensory evoked potentials data. Arch Neurol 1988;45:1312-20.

18 Nathan PW, Smith MC, Cook AW. Sensory effects in man of lesions of the posterior columns and of some other of lesions of the posterior columns and of

19 Beric A, Dimitrijevic MR, Lindblom U. Cortical evoked potentials and somatosensory perception in chronic spinal cord injury patients. F Neurol Sci 1987;80:333-42.

20 Nathan PW, Smith MC, Deacon P. The corticospinal tracts in man. Course and location of fibres at differen segmental levels. Brain 1990;113:303-24.

21 Walker JB. Modulation of spasticity. Prolonged suppression of a spinal reflex by electrical stimulation. Science 1982;216:203-4.

22 Dimitrijevic MM, Dimitrijevic MR. Clinical practice of functional electrical stimulation. In: Illis L, ed. Spinal cord dysfunction. Vol III. Functional stimulation. Oxford: Oxford University Press, 1992:168-74.

23 Woolf CF. Segmental afferent fibre-induced analgesia: transcutaneous electrical nerve stimulation. In: Wall PD transcutaneous electrical nerve stimulation. In: Wall PD, Livingstone, 1989:884-96.

24 Goldberg JM, Lindblom U. Standardized method of determining vibratory perception thresholds for diagnosis and screening in neurological investigation. $\mathcal{f}$ Neurol Neurosurg Psychiatry 1979;42:793-803.

25 Fruhstorfer H, Lindblom U, Schmidt WG. Method for quantitative estimation of thermal thresholds in patients. f Neurol Neurosurg Psychiatry 1976;39:1071-5.

26 Hosobuchi Y. Subcortical electrical stimulation for control of intractable pain in humans. Report of 122 cases (1970-1984). F Neurosurg 1986;64:543-53.

27 Levy RM, Lamb S, Adams JE. Treatment of chronic pain by deep brain stimulation: long term follow-up and review of the literature. Neurosurgery 1987;21:885-93.

28 White JC, Sweet WH. Pain and the neurosurgeon Springfield: Charles C Thomas, 1969:743-8.

29 Swett JE, Law JD. Analgesia with peripheral nerve stimulation: absence of a peripheral mechanism. Pain 1983;15: 55-70.

30 Wiesenfeld-Hallin Z, Hallin RG, Persson A. Do large diameter cutaneous afferents have a role in the transmission of nociceptive messages? Brain Res 1984;311:375-9.

31 Ochoa JL, Yarnitsky D. Mechanical hyperalgesias in neuropathic pain patients: Dynamic and static subtypes. Ann Neurol 1993;33:465-72.

32 Campbell JN, Raja SN, Cohen RH, Manning DC, Khan AA, Meyer RA. Peripheral neural mechanisms of nociception. In: Wall PD, Melzack R, eds. Textbook of pain. London: Churchill Livingstone, 1989:22-45.

33 Lindblom U, Verillo RT. Sensory functions in chronic neuralgia. $\mathcal{F}$ Neurol Neurosurg Psychiatry 1979;42:422-35. Campell IN, Raja SN, Meyer RA, Mackinnon SE Myelinated afferents signal the hyperalgesia associated Myelinated afferents signal the hyper
with nerve injury. Pain 1988;32:89-94.

35 Price DD, Bennett GJ, Rafii A. Psychophysical observations on patients with neuropathic pain relieved by symtions on patients with neuropathic pain
pathetic block. Pain 1989;36:273-88.

36 Torebjörk HE, Lundberg LER, LaMotte RH. Central changes in processing of mechanoreceptive input in capsaicin-induced secondary hyperalgesia in humans. f Physiol 1992;448:765-80.

37 Leijon G, Boivie J. Central post-stroke pain-the effect of high and low frequency TENS. Pain 1989;38:187-91.

38 Bates JAV, Nathan PW. Transcutaneous electrical nerve stimulation for chronic pain. Anesthesia 1980;35:817-22.

39 Cole JD, Illis LS, Sedgwick EM. Pain produced by spinal cord stimulation in a patient with allodynia and pseudo-
tabes. F Neurol Neurosurg Psychiatry 1987;50:1083-4.

40 Weddell AGM. 'Activity pattern' hypothesis for sensation of pain. In: Grenell RG, ed. Neural phys

41 Wall PD, Noordenbos W. Sensory functions which remain in man after complete transection of dorsal columns. in man after complete

42 Glendinning DS, Vierck CJ. Lack of a proprioceptive deficit after dorsal column lesions in monkeys. Neurology 1993;43:363-6.

43 Greenberg JA, Kaplan PW, Erwin CW. Somatosensory evoked potentials and the dorsal column myth. $f$ Clin Neurophysiol 1987;4:189-96.

44 Davidoff RA. The dorsal columns. Neurology 1989;39: 1377-85.

45 Chiappa KH. Evoked potentials in clinical medicine. New York: Raven Press, 1990

46 Cusick JF, Myklebust J, Larson SJ, Sances JA. Spinal evoked potentials in the primate: Neural substrate. 7 Neurosurg 1978;49:551-7.

47 Melzack R, Wall PD. Pain mechanisms: a new theory. Science 1965;150:971-9. 